\title{
The power of stories from within: The Dingleton Community relocation
}

\author{
Mouton, Dawid P \\ University of the Free State \\ moutondp063@gmail.com
}

\begin{abstract}
In a context of change and transition a degree of uncertainty and anxiety can be expected, and perhaps even the need to reflect on the forces affecting change. Such reflection may happen through a narrative evaluation of people's lived realities as it relates to the forces affecting such changes. This process may create an opportunity to recall, review and re-author dominant narratives in order to deal with change. The article, drawing on the stories of some people affected by the relocation of the Dingleton community in the Northern Cape, highlights the fact that the power of narratives of ordinary people has the potential to influence their response to forces of change. This is not an attempt to present detailed stories or a technical discussion on the notion of power, but rather aims to highlight only those aspects of selected narratives that demonstrate the power people's own stories may have.
\end{abstract}

Keywords

Stories, power, disruption, transition

\section{Introduction}

Change and transition can often have a disruptive impact on people's lives, and may introduce a certain degree of uncertainty and anxiety. Such disruptive experiences and the resultant impact on the lives of the affected have the ability to introduce a possible process of reflection. This reflection on the lived reality of being in a context of change and transition can then lead to a renewed evaluation of people's foundations, potentially uncovering counter-forces in their lives that may help them to deal with the forces affecting change and the change itself. These serve to recall and often review and re-author dominant narratives in people's lives, 
particularly with regards to the power of these narratives and the meaning thereof in the lives of people. This paper aims to demonstrate the power of, or at least parts of, narratives of a few people affected by the relocation of the Dingleton community in the Northern Cape. It is a small community in the process of being moved to the nearby town of Kathu due to the expansion of mining activities.

Broadly, a narrative approach was followed in the study allowing for, what Muller et al (2001:76) call, 'research participants/co-researchers' to take centre stage in the telling of their own stories. With a 'narrative approach' the author understands that the real-live stories of people are given precedence. This social-constructionist approach takes serious the real struggle of people in real contexts and how this reflects in their stories (Muller 2004:295). However, this approach offers the opportunity to move beyond the local context, and beyond mere hermeneutics towards a more 'reflexive and situational embedded epistemology and methodology' (Muller 2011:3) The main aim of research within this paradigm is not in the first place to effect immediate change, but to listen to the stories of people (Muller, Van Deventer and Human 2001:76). Through this new meaning may emerge and hope may be found.

Conversations referred to in this paper took place during March 2014. The paper does not aim to present detailed stories or a technical discussion on the notion of power, but rather aims to highlight only those aspects of selected narratives that demonstrate the power stories have on people and how it give impetus to people's understanding of their lives within a changing environment.

\section{The backdrop to these stories}

Originally built in the 1950's by the then state-owned company ISCOR, the mining town, then called Sishen, was intended to primarily house white employees working on the mine (Anglo American 2011; Business Day Live 2014). The mine is now owned by Kumba Iron Ore (KIO), a subsidiary of the Anglo American plc group (Anglo American 2007). During the 1980's, after the original inhabitants were moved to Kathu due to operational considerations, the houses were sold to private individuals, mainly so-called Coloured people. In 2011 the mining company owned only about $20 \%$ of the 
property in town (Anglo American 2011). The name of the town changed to Dingleton in 1990. Due to continuous mining expansion, the town is now located very close to the mining area and is consequently increasingly exposed to a number of environmental and other hazards related to mining activities. It has been suggested that complaints by residents regarding the deteriorating infrastructure and the increasing proximity of mining activities led to an undertaking by KIO to relocate the community to the nearby town of Kathu as part of the 'mine's environmental management and social development plans' (Business Day Live 2014).

According to a senior employee ${ }^{1}$ on the project (personal interview, March 2014), the process was designed to follow the guidelines of the World Bank which included an extensive stakeholder engagement initiative between 2007 and 2013. Resettlement would take place in a designated area in Kathu where residents would have the opportunity to still live in a 'pseudo' Dingleton community. In the March 2014 interview, the employee suggested that the vast majority of residents support the resettlement and that almost $85 \%$ of residents had already signed an agreement for compensation with KIO. In November 2013 the heritage authorities granted approval for the relocation of graves in the area and in December 2013 the board of Kumba granted approval for the approximately $\mathrm{R} 4.2$ billion relocation which is planned to take between 4 to 6 years, making this 'the biggest community relocation by an Anglo American unit to date' involving around 3131 residents from Dingleton (Business Day Live 2014). The project is expected to be completed by 2017 and in its entirety would include the building of 'houses for previous owners, rental accommodation, schools, churches, and a police station' (Business Day Live 2014) in addition to other community facilities. While some residents may be resisting the resettlement project for different reasons, the majority apparently view it as a welcome change in their circumstances.

Various conversations with residents and the project staff for the resettlement project revealed the following with regards to the perceived beneficial aspects of the project.

1 To protect the identity of the employee, no specific reference to his/her identity can be made. 
Benefits to community will include amongst others:

- Increase in property value

- Newer and more modern infrastructure

- Better facilities and easier access to social services

- Eliminate unsafe journeys to Kathu for services needed

- Enhanced employment opportunities.

- All relocation and property transfer costs will be paid by Kumba, as well as the difference in property taxes and rates for 25 years and capital gains tax that private property owners might incur as a result of the resettlement.

Benefits to Kumba Iron Ore

- Expansion of mining activities and extension of the 'life of mine' (LOM)

- Social responsibility profile

- Reducing related risk profile

- CEO of Kumba Norman Mbazima, in a press release on 12 December 2013, said the following (Anglo American 2013):

'Kumba is committed to operating in a way that takes into account not only the financial implications of business decisions, but also the social and environmental impact it has on the community. A hallmark of this project is the extent of participation and positive contribution by the provincial and local government and community representatives - with an extensive consultation at every step of the process.'

However, there are those residents who, despite acknowledging certain benefits expected to derive from the resettlement project, are still convinced that Kumba is unfairly advantaged in terms of perceived power hierarchies in the context of the negotiations. Some are convinced that, based on their understanding of the future financial benefits for the mining company, residents are entitled to even more compensation than what is currently offered. Are these claims fair in the light of the fact that some R 4.2 billion 
will be spent on the project? It is not the intention with this paper to make a judgment on this. Instead, the author wishes to present some stories of residents here in order to highlight the impact of those stories on the perceptions and sense of agency of those residents. However, one should also not be naive with regards to the complex nature of development induced displacement and relocation (DIDR) projects, and the history of imbalanced power structures of such projects. Hence, without going into too much detail and as a brief introduction only, just a few notes will now be presented on this topic of DIDR to also show that in a broader sense the story of DIDR exhibits its own dimension of power.

DIDR has shown to significantly affect overall well-being of individuals and communities. It has been found that forced resettlement and migration can be linked to a weakening in mental well-being (Hwang, Cao \& Xi 2012:1765, 1771; Cao, Hwang \& Xi 2012: 1130, 1137). It has also been argued that the distinction between voluntary and involuntary community resettlement for development purposes is not always as clear-cut as one would believe (Morris-Jung \& Both 2010:218). Schmidt-Soltau \& Brockington (2007:2184) argue that there is always an involuntary element to it, and that it remains a complex matter. Given the ambiguity in terms of voluntary and involuntary resettlement, one could assume that the same may be true even for a process that may not be regarded as a forced removal process, especially since an unequal power relationship may be assumed to exist between developer and community (Aronsson 2009:38-39). This is also a view held by some co-researchers from the community.

Although the stories to be presented here deals with the broader experiences related to this relocation, the author wishes to particular demonstrate how these stories have a certain influence on the responses of these coresearchers in the face of changing circumstances.

\section{Why stories?}

But why would one want to tell stories of other people? Why is it important to tell the stories of Dingleton's people? It is perhaps because stories reflect the lived reality of people. It reflects the search for the sacred. And is the search for the sacred in the mundane lived reality of ordinary people not the concern of theology and Practical Theology in particular? Taking lead from 
Ruard Ganzevoort's (2009) notion of lived religion, I believe that stories are in fact of concern for Practical Theology and Practical Theological research. The dynamics of people's stories tell us not only of how they live life, but also how they are shaped by life in the presence of God.

With specific reference to the issues of power, stories reveal people's understanding of the powers influencing their lives and of the particular powers they perceive to exert on life. After all, Foucault (1978:93) suggested that power is everywhere and has the ability to exert influence from all levels and from everywhere. It is not merely a hierarchical phenomenon, but it can be exerted and experienced from all levels - power can be experienced from above as well as from below. Perhaps the great value of such an understanding is that it allows for people to identify and evaluate those powers that can possibly affect them, and then choose to focus on those powers that shape their understanding of life and the meaning thereof. Yes, it may not always be possible to limit the effects of a particular power phenomenon in one's life, but when placed in the context of a bigger and broader narrative, these powers may be re-interpreted to give new meaning in life. Here the author wants to demonstrate that even the stories that sometime reflect on power issues has a power of its own, often influencing people's choices and responses.

In the telling of the story, themes on power that may have been obscured by a dominant storyline may emerge as moments of hope in people's lives. Perhaps some may fancy it to be an act of fiction writing that provides an avenue for escapism from reality. However, as Muller et al (2001:7696) demonstrated, it may very well be that this fictional nature present in people's narratives, and in a narrative research approach, opens up possibilities for previously 'hidden' stories (with the potential to influence for the better) to emerge in the narratives of people and for its influences to be re-interpreted in order to gain new understanding, meaning and hope.

The conversations referred to in this paper took place during March 2014. At that time much of the stakeholder engagement had already taken place and the bulk of the residents had agreed to the move (this paper will not explore the issue of whether this relocation is happening reluctantly or not). Civil works at the site of relocation had already started and seemed to be progressing. However, the official 'move' of people had not really started yet. 
A broadly narrative approach was followed with co-researchers/narrators presenting their stories in their own way. Furthermore, the very transitional nature of the 'moment of praxis', as Muller (2004:293) refers to it, calls not only for a narrative approach, but for a post-foundational Practical Theology where due recognition is given to the meaning of context and diversity in the storied and lived reality of people. This moment of praxis which refers to the fact that experience is always 'local, embodied, situated' (Muller 2005:2) becomes the meeting ground between Practical Theology and a post-foundational approach. In the context of this paper the event of the relocation of the Dingleton community and that which surrounds it can be viewed as the 'moment of praxis' that gave rise to particular embodied experiences within that context, whilst at the same it gave rise to this research project. In line with the thinking of Muller et al (2001:78) the purpose of this research project and this paper is not necessarily about the facilitation of change, but rather about the reflective listening to the stories of people.

In a transitional context, such as that of the Dingleton community at the time of the conversations, the challenge is often about dealing with continuously changing fields of meaning, making it a necessity to follow an epistemological and methodological framework that enables reflection rooted firmly in situational experience. Julian Muller (2011:2) argues that such an approach can be found within a post-foundation paradigm, both in terms of epistemology and methodology. Muller (2005:2) also argues that such an approach forces a rediscovery of Practical Theology as an endeavour that involves 'a reflection on practice, from the perspective of the experience of the presence of God'. The big advantage of this approach is that stories are told, listened to and interpreted and re-interpreted from 'within' and not from a perspective of the so-called objective stance. It is the narrative within its particular context and the meaning for and within that context that gains prominence. In this regards the approach followed here was very much influenced/directed by that proposed by Muller et al (2001:76-96), who argue for an integrated approach whereby theoretical considerations, methodological choices, as well as the process of research all be considered as part of the epistemological framework for doing research. The role of co-researchers as primary narrators and key participants in the process is emphasized. The value of this proposed approach (the 'ABDCE 
model') probably lies in the prominence, relevance and legitimation it gives to the 'now', starting off not only with the 'action (A) 'of the 'now', but with story of the action itself. Due emphasis is placed on reading and conversing on this 'action' in light of contextual factors, current and historical, as background (B) for this story/research. In this the research is not only allowed to develop, but the very meaning of the story/research for the co-researcher starts developing (D), leading to an eventual climax (C) where integration can take place to an extent and where meaning has been developed. In the end (E), its open-endedness highlights the idea that in narrative research it is not so much about providing easy answers, but to lead to an openness where new questions may be asked and new possibilities develop so that this 'story' may lead to new and other related and liberating stories.

\section{Whose story? What power? The stories from within}

So, whose stories and what stories should be important to consider in this context? The stories of residents? Perhaps the story of the mining company or that of government? Should the one story be regarded as more important than the other? Or do they all have significance within a particular contextual embeddedness? Narratives from some residents were selected demonstrating a different approach to dealing with the force of disruption and change. As indicated before, these narratives will not be presented in detail. Rather, by way of referring to each and by giving brief background, each will be reflected upon specifically with regards to the narrators' ways of finding meaning, hope and a means to cope with the imminent changes. No detail that may reveal or suggest the identity of the narrators will be included in the discussion.

Two of the narratives presented here deal with the experiences of prominent and influential church leaders. Both these leaders acknowledge the fact that significant moral decay has taken place in Dingleton over the last number of years. They also agree that due to infrastructure deterioration, a lack of services and the increased exposure to mining related hazards, the relocation to Kathu could be regarded as a potentially positive development. The building of new houses, well-maintained infrastructure, closer proximity to amenities and services, less traveling and improved medical services accounted amongst the positives identified. Common concerns 
raised with regards to the move to Kathu included the further decline of a sense of community, perceived higher living costs, perceived skewed power relations, mistrust and inequality, as well as uncertainty with regards to personal and household sustainability, especially for pensioners and those in lower income ranges. On the issue of dignity both agreed that the perceived skewed power relations and the continuation of a 'regime' of inequality is an infringement on the dignity of the people of Dingleton. However, on another level they also agreed that the current living conditions in the town and the moral decay also does not witness to a dignified way of living. At least the conditions in Kathu, they agreed, would be more enabling for a sense of human worth and dignity to be maintained.

Interestingly though was the fact that the narration of the story of the one church leader revealed a strong emphasis on issues of compensation and the question of uncertainty, whilst the other often highlighted the fact that God creates new opportunities during times of change and crisis, but without denying the importance of the concerns raised. In the former case there appeared to be a pre-occupation with the notion that the dominant power lies with the mining company. A sense of helplessness in the light of the 'might of a big company' seemed to be a dominant theme in the narrative of this person. Perceived well-being was also mostly evaluated and expressed in relation to material compensation and providence. In this case a relatively strong sense of powerlessness could be observed. Power seems to be something outside of the person (with the mining company) and, in the current context and circumstances, appears to be working against him and his expectations. Although an active faith in God is also proclaimed, at least at the time of the conversations, it appeared that prominence was given to the impact of other external factors. This was somewhat in contrast to the narrative of the other church leader. Although he acknowledged the challenges and the reality of skewed power relations, emphasis was placed mostly on God as the provider, sustainer and the creator of new opportunities amidst changes and challenges. He therefore does not view the planned relocation necessarily as a 'new disruption', but rather as a 'new opportunity'. For him the knowledge and experience of God's providence, both personal and with regards to his faith community, is a source of hope - a reason to believe that there could be a meaningful life in their new context. Change is seen as constant, uncovering opportunities 
for growth and creating the need to re-evaluate one's own understanding of purpose and discipleship. Although issues of trust, inequality and injustices are real, he finds solace in the fact that God is just and trustworthy. Thus, instead of succumbing to a feeling of being overpowered by the might of a big mining company, he acknowledges the imbalance in power, but deliberately look to God and his understanding of God as the driving force for both his personal and ecclesial life. Hence, although power is also to be perceived as being situated outside of the person, it is viewed as an enabling force because of the belief of the indwelling of the Spirit of God.

Another conversation held, was with a family consisting of an elderly mother, her son and his wife. Both the mother and the son owned very neat and big houses in Dingleton (for which they would be compensated), in addition to property elsewhere. This family also agreed that, for similar reasons as listed above, moving to Kathu would be an improvement. Again, the narrative of their experience related to the relocation process was dominated by issues of compensation and a sense of being overpowered by the might of a big mining company ('a giant dictating to the small person'). Their story, as they told it, revealed a strong reliance on material means for their identity, their sense of stability and dignity, and as a means of being in control of their own lives. Despite appearing to be rather well-off, much was made of uncertainty with regards to a sustainable livelihood, especially for the elderly mother. Other issues that appeared to be bothering the family, in addition to a strong conviction to be able to negotiate on an individual level, include the design of the houses, the race of neighbours, and the inconvenience of the relocation. Although the family also came out strongly against the skewed power relation between the community and the mining company with regards to the process, it appears that they draw much of their energy from a strong awareness of their individual priorities. Just as in one of the previous cases, the narrative of this family revealed a relationship with God which is lived out in a faith community. However, despite God being significant in their lives, their dominant story appears to be driven by the power of individual satisfaction and material compensation. Even though they seem to be well-off, as mentioned earlier, a strong perception of uncertainty and dissatisfaction seem to dominate their narrative.

The last narrative reflected upon here is that of a couple of elderly men who originate from Angola. These men were separated from their families when 
civil war broke out in Angola. They had to leave their wives and children behind when they fled the country to seek refuge in Namibia (then South West Africa). For some time they lived in a refugee camp before they were given the ultimatum to either return to Angola, which they could not do at that time, or join the South African Defence Force (SADF). They remained part of the SADF in Namibia until the country's independence from South Africa, at which point they had to move to South Africa. In the meantime they re-married and started new families. After their unit was disbanded by the new democratic government they were left to find their own way and eventually ended up in Dingleton where they bought property and settled. Even though they have integrated into the community fairly well, it has been a tough time initially, particularly as they could not really speak Afrikaans. Despite all the pain, the difficulties, the broken promises and the challenges of integrating into a strange community, they have managed to maintain their family and 'micro' community identity and cohesion. One is immediately struck by the long list of challenges that permeate almost all phases of their narratives. Yet, even more striking is their positive outlook on life. While they were so many times faced with situations that left them no other choice but to move on and try to resettle somewhere else, their stories witness to a deep believe that all is in God's hands.

They almost casually take note of unfair deals that life often hands out, and rather choose to focus on the faithfulness and fairness of God. For them the relocation to Kathu is like a prayer answered as they do not see the current conditions in Dingleton as conducive to the strengthening of dignity or a sense of community. A profound trust and hope in God seems to be the mainstay of their ability to deal with forced changes in a positive manner. Although they know that it is not guaranteed that KIO will keep all its promises, they hold on to a history that witnesses about a God who always keeps His promises, who always provides and who always protects. For them God is not someone they will have to search for in Kathu. Instead they live with the conviction that God is everywhere and that $\mathrm{He}$ is in Kathu as well.

Apart from their deep faith in God, their stories further revealed a deep sense of the holding power of strong family relationships. The family is the space where God protects and provide for them. Therefore, instead of spending too much time thinking about issues of compensation, they rather 
continue to strengthen their family relationships as they believe that it is through maintaining healthy family units that they will be able to support each other and to survive through tough times. Yes, they do acknowledge a world full of various powers and forces that impact on their lives. They do acknowledge the fact that they often cannot stand up against these forces. However, this does not disempower them. Instead, this realization moves them to leave it all in God's hands and to rather focus on the two things that have kept them going - their faith in God and their families.

\section{Do these stories mean anything?}

Listening to these stories enabled the identification of different powers operating in the lives and perspectives of people at this particular time in their lives. It became clear that those aspects that enjoyed prominence in the stories of the co-researchers strongly influenced their experience of the pending relocation. Who and what they perceived to be important in this process impacted on their own sense of control, hope and meaning within their changing context. Where prominence was given to the power of the mining company or the issues of stability, satisfaction, compensation and sustenance, a stronger sense of frustration and powerlessness emerged in the narratives. On the other hand, where faith in God (the search for the sacred in a lived reality) and a strong reliance on communion (family ties for instance) had prominence, the power from the 'stories form within' provided a greater sense of meaning and meaningfulness. Such is this sense of meaning and meaningfulness that it provides an alternative to a narrative dominated by forces from outside. Even if these forces may be a threat to the very sense of stability and meaningfulness. In each of the stories issues of identity, values, and faith featured. It seems that where perceived powers of change are viewed in light of the reality of God's presence and providence, there is an affirmation of identity, values and faith. Where this is not the case feelings such discontent, uncertainty and frustration becomes stronger forces.

Helping people in a context of change to realize the various ways of authoring and re-authoring their stories to find hope again emerge as an important endeavour of this Practical Theological research. In this way 'closed' stories become re-opened and open-ended with a new possibility for re-authoring. The re-interpreted or re-authored story now has the 
power to provide impetus to a psycho-spiritual response that may offer a way of finding hope and meaning again. In turn resilience is build, faith is strengthened and new meaning and purpose is possible even in the light of a possibly unwelcoming change. Such a task would fit perfectly within the realms of Pastoral Care and Practical Theology as praxis of care and restoration.

Unfortunately the full stories of these narrators cannot be captured here adequately. Also, one should be careful not to read any of these narratives with a moralizing lens. Instead, the reader should bear in mind that only specific elements of each of these narratives were chosen to be presented here to illustrate how people, knowingly or unknowingly through their own narratives, make a choice as to which powers and forces to recognize in their lives and what influence and authority is afforded to it. Furthermore, these examples and excerpts serve to illustrate that it is possible to identify, through narrative means, and to isolate language of power in the stories of people when they are allowed to narrate their stories on their own terms and from within their own contexts.

\section{Conclusion}

In a way this is a rather 'simple' paper, something that is almost paradoxical in the light of the search for elements of power perceptions in the narratives presented here. However, this serves to highlight that through the ordinary narratives of ordinary people, using a post-foundation narrative approach, one may be able to illustrate how stories themselves generate a particular understanding of powers and forces and eventually direct people's responses to changes and crises. As illustrated, the perceived dominant power reflected in the story and the power of the story from within plays a significant role in how people choose to deconstruct their lives, to find meaning in their circumstance and deal with change and transition. When the author's version of these narratives were read back to the its narrators it opened up the space for reflection, re-interpretation and new meaning, as well as a new sensitivity to the powerful elements in their narratives and how it affected opinion, perception and responses. This paper, as a work in progress, can certainly be enhanced with a more thorough and nuanced discussion on the concept of power, also in relation to postfoundationalism, narrative methods and Practical Theological research. 


\section{Bibliography}

Anglo American. 2007. Proposed Relocation of the Dingleton Township and Community. [Online] Available at: http://www.kumba.co.za/news_ article.php?articlelD=287. [Accessed 27 November 14].

Anglo American. 2011. Kumba iron ore responsibility report 2010 . [Online] Available at: http://www.kumba.co.za/reports/kumba_ar2010/ responsibility/if_pi_relocation.php. [Accessed 27 November 14].

Anglo American. 2013. Relocation of Dingleton community approved. [Online] Available at: http://www.bdlive.co.za/national/2014/11/25/kumba-http:// www.kumba.c0.za/news_article.php?articlelD=2011. [Accessed 27 November 14].

Aronsson, I 2009. The paradox of local participation in forced displacement and resettlement caused by the development process. Revista Română de Sociologie, $\mathrm{xx}(1-2): 37-59$

Business Day Live. 2014. Kumba sets bar high in building of 'new Dingleton' as mine expands. [Online] Available at: http://www.bdlive.co.za/ national/2014/11/25/kumba-sets-bar-high-in-building-of-new-dingleton-as-mineexpands. [Accessed 27 November 14].

Cao, Y., S. Hwang \& J. Xi. 2012. Project-induced displacement, secondary stressors, and health. Social Science \& Medicine, 74:1130-1138

Foucault, M 1978. The History of Sexuality, Volume One: An Introduction. Translated by Robert Hurley. New York: Pantheon Books.

Ganzevoort, RR 2009. Forks in the Road when Tracing the Sacred. Practical Theology as Hermeneutics of Lived Religion. Presidential address to the $9^{\text {th }}$ conference of the International Academy of Practical Theology. 2009.

Hwang, SY Cao \& J Xi 2012. Project-induced migration and depression: A panel analysis. Social Science \& Medicine, 70:1765-1772

Morris-Jung, J \& R Both. 2010. The blurred boundaries of voluntary resettlement: A case of Cate Tien National Park in Vietnam. Journal of Sustainable Forestry, 29:202-220 
Müller, JC 2004. 'HIV/AIDS, narrative practical theology, and postfoundationalism: The emergence of a new story', HTS, 60, 1\&2, 293-306.

Muller, JC 2005, A post-foundationalist, HIV-positive practical theology. Paper presented at the International Biennial Conference of the International Academy of Practical Theology, Brisbane, Australia, 25-29 June.

Muller, JC 2011 2001. 'Postfoundational practical theology for a time of transition', HTS Theological Studies, 67(1), Art. \#837, 5 pages. doi.10.4102/hts.v67i1.837

Muller, JC, Van Deventer, W \& Human, L 2001. 'Fiction writing as metaphor for research: a narrative approach', Practical Theology in $S A, 16,2,76-94$.

Schmidt-Soltau, K \& D Brockington 2007. Protected Areas and Resettlement: What Scope for Voluntary Relocation? World Development, 35(12):2182-2202 